\title{
Collaborative Broker for Distributed Energy Resources
}

\author{
João Carlos Ferreira \\ ADDETC - ISEL \\ Lisbon, Portugal \\ jferreira@deetc.isel.ipl.pt
}

\author{
Alberto Rodrigues da Silva \\ IST and INESC-ID \\ Lisbon, Portugal \\ alberto.silva@acm.org
}

\author{
Vítor Monteiro and João L. Afonso \\ Centro Algoritmi and Univ. Minho \\ Guimarães, Portugal \\ \{vmonteiro and jla\}@dei.uminho.pt
}

\begin{abstract}
In this work is proposed the design of a system to handle Distributed Energy Resources (DER) that is a new reality due to the Electric Vehicles (EV), Micro Generation (MG) and the open Electrical Markets (EM). This upcoming reality brings the need of the 'old' central energy control to be installed locally. For that we propose a local energy broker, responsible to handle local energy flow, exchange energy with 'big' market players and based on a collaborative approach, promote user's participation to increase systems knowledge. The broker uses an Information Communication Technology (ICT) network in order to establish a collaborative communication between all the involved parts.
\end{abstract}

Keywords - Distributed Energy Resources, Data Mining, Broker, Electric Vehicle, Energy Market, Smart Grids, Vehicleto-Grid, Collaboration, Microgeneration

\section{INTRODUCTION}

New paradigms are emerging, like the EV, MG, the Smart Grids (SG), where we will have small energy producers with a MG. In this context, the Electrical Market (EM) is the consequence of the deregulation the use and production of electricity, where power suppliers and consumers are free to negotiate the terms of their contracts. Also the EVs integration on current electrical distribution network, without violating the system's technical restrictions, requires electrical data consumption analysis and smart charging approaches, where the EV batteries charging or discharging processes needs to be coordinated among the several users and EV can play an important role in the MG, because they are able to store production excess and deliver energy in the peak of consumption. In this complex scenario, there is a need of an information system to handle electricity change, determine profits or values to pay and help the users on this process. Because there is a common goal (EM participation), the proposed system can benefit from user participation and users community (users with similar profiles can be identified). These subjects converge under the name of DER as part of an intelligent power system to construct a hybrid, fundamentally different architecture for an ICT-network enabling the power grid to flexibly accommodate novel devices or clusters of devices. Several initiatives are taking place on this topic: (1) Intelligrid [1], a program in the United States executed by EPRI; (2) Gridwise [2]; CRISP project [3]; (3) European initiative under the program EU_DEEP-project [4] and the activities; and (4) IREDcluster [5]. As described in various articles in literature
$[6,7]$ there are many implications for the grid when making a transition from centralized to decentralized control with merely some central coordination. When compared to hierarchically operated electricity grids with power centrally generated at high voltage levels on a large scale delivering electricity to consumers on lower voltage levels in the network, SG [8] offer a number of challenges for technological research. Our work proposes the creation of a collaborative broker system to handle $\mathrm{EV}$ and $\mathrm{MG}$ integration on EM, supported by users collaborative process, transaction data integration and central information repository knowledge, where we can store past experience to help on solving problems such as: (1) the excess of energy produced by MG should be distributed along the MG to the $\mathrm{EV}$ or to consumers, minimizing the use of the distribution network. In this context, arise the Energy Storage Systems (ESS), which can store the excess of energy produced by MG, and deliver this energy when it is necessary. These ESSs are controlled by the broker (transactions account); (2) the price of the electricity should be determined taking into account the production capacity, because the MG will be based on renewable sources with different profiles of production; (3) the interaction between the $\mathrm{MG}$ and the consumers should be implemented taking into account a maximization strategy to the user. To obtain a good contribution with electrical energy to the electrical power grid by the producers, the EM should implement attractive benefits to buy or to sell. The control of energy flow between the MG, taking into account the EM, the consumers and the sellers, is coordinated by the broker (e.g transaction's account and user's alerts to change consumer behavior, see section $\mathrm{V}$ ).

The proposal central information repository can store and manage historical data on electricity consumption and production. This information should come in a near future from the smart meter, for this work purposes we simulate consumptions and user behavior [10]. From this central repository it is possible the development of tools to extract knowledge from past electricity exchange log files, EM prices, renewable energy availability and capability, consumed or delivered energy if EV is plugged at home, and electrical distribution network constraints. Also, the social networks are integrated as a tool to share and spread useful related information. This central repository will be later, in a SG environment, a fundamental module to store all kinds of SG data and to solve the problems of different data format diversity. 


\section{MICRO GENERATION}

Nowadays, the MG emerges as a necessity to reduce the greenhouse effect caused by pollutant sources of energy. However, associated with the EM and the increasing in the technological development, the micro generation of electrical energy has a great potential to the consumers, and to the distribution grid.

The main sources of energy in a MG are wind and the sun, and the electrical energy is obtained through micro wind turbines and solar photovoltaic panels. These sources of energy are the most common and the easier to implement in the MG. Presently, this produced energy is provided to the electrical power grid without any concern about the EM or the electrical power grid capability to receive energy. In a smart grid context with ESS, like batteries, EVs, capacitors or flywheels, the energy produced in excess from the MG can be stored in these systems. Posteriorly, this stored energy is used to help the electrical power grid taking into account: (1) the energy produced by other sources of energy. When is required to provide a great amount of energy, as during the EVs fast charging, on the other end the energy provided from electrical power grid, can be provided from the ESS. It is also important to provide energy to the power grid in transitory moments as the consumers' consumptions peaks; (2) the EM, to buy or to sell with the best price. This is most important to the EV owners, because with the vehicles plugged in the MG they have the potential to discharge the batteries until the maximum allowed. This is why the Vehicle-to-Grid (V2G) has a fundamental role in the smart grid.

In this context, from the point of view of the electrical power grid, with the proximity between the MG and the consumers, there are reduced flows of power along the transmission and distribution lines, and consequently, the losses are lower. With this proximity, encompassed in the $\mathrm{MG}$, the possibility of failures occurrence is reduced.

\section{ELECTRIC VEHICLES}

The recent increase of the interest in EVs using batteries represents a gain for independence relatively to the unstable costs of the oil in the international markets, and contributes to reducing the emission of greenhouse gases, like $\mathrm{CO}_{2}$. However, with this increasing use of batteries, it is intended that the methods for charging and discharging batteries are beneficial, not only to the lifespan of the batteries, but also to preserve the power quality on the electrical power grid. In this sense, it is very important to provide EVs with equipment for charging and discharging the batteries, as described in [9]. This equipment shall guarantee that the batteries are charged with the best possible algorithms, according to the information given by the batteries manufacturers, in order to extend as much as possible the lifespan of the batteries (during slow charging process), or to speed up the charging time, without compromising the batteries lifespan (during fast charging process). At the same time, this equipment must ensure that batteries are charged from the electrical grid ensuring the power quality in electrical power grid. During the discharge of the batteries, when the stored energy in batteries is delivered to the electrical power grid the power quality also should be ensured. This equipment must also assure that only a previously agreed (by the electric vehicle owner) amount of energy will be delivered back to the electrical grid (e.g., if a long trip is planned to occur soon, the equipment will not allow the discharging of the batteries).

In typical EVs, when it is necessary to charge the batteries, the energy comes from the electrical grid to the batteries in unidirectional mode, without any control in electrical grid. However, in a SG scenario, and using bidirectional chargers, aiming the $\mathrm{V} 2 \mathrm{G}$ concept, the batteries can be charged or discharged, from the moment that the vehicle is plugged to the electrical power grid (Figure 1), according to a compromise assumed between the EV owner and the electrical grid company, and controlled by a collaborative broker as described in this paper.

\section{DISTRIBUTED ENERGY RESOURCES AND THE ENERGY MARKETS}

Distributed Energy Resources (DER), small-scale power generating technologies close to energy loads, are expected to become an important part of the future power system. MG and EV will play an important role in this process and nearby community will use this power because the network distribution allows it. Since distributed energy resources are installed near the loads, they are likely to be installed on lowvoltage below $25 \mathrm{kV}$ distribution systems. The distribution systems also account for the higher percentage of system losses compared with the higher voltage transmission systems, causing an improvement of the overall efficiency of the system. DER has the problem of variability (changes in load), uncertainty (supply contingencies) and unpredictability (renewable generation).

Main important fact is that $\mathrm{EV}$ can store local $\mathrm{MG}$ production excess and users' can tune their consumer behavior in part based on $\mathrm{MG}$ production, i.e. they can develop a collaborative process based on energy production information they can start/stop washing machines and other equipment that don't have a time constrain obligatory.

Energy market has historically been monopolized and governmentally regulated because of its utmost importance. Like water, energy is essential for life and firm grip on it was a logical choice of policy makers. With general globalization, such monopolized, nontransparent and market detached approach has become economically and politically unacceptable. To leave political influences aside as they surpass the scope of this article, global economic development demanded a change. Despite the efforts to save energy and use it as rational as possible, which are getting

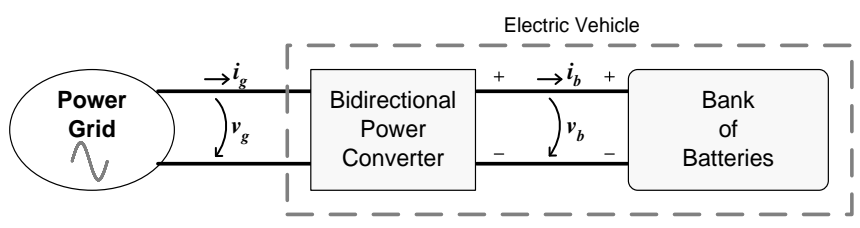

Figure 1. Integration of the EV in the power grid. 


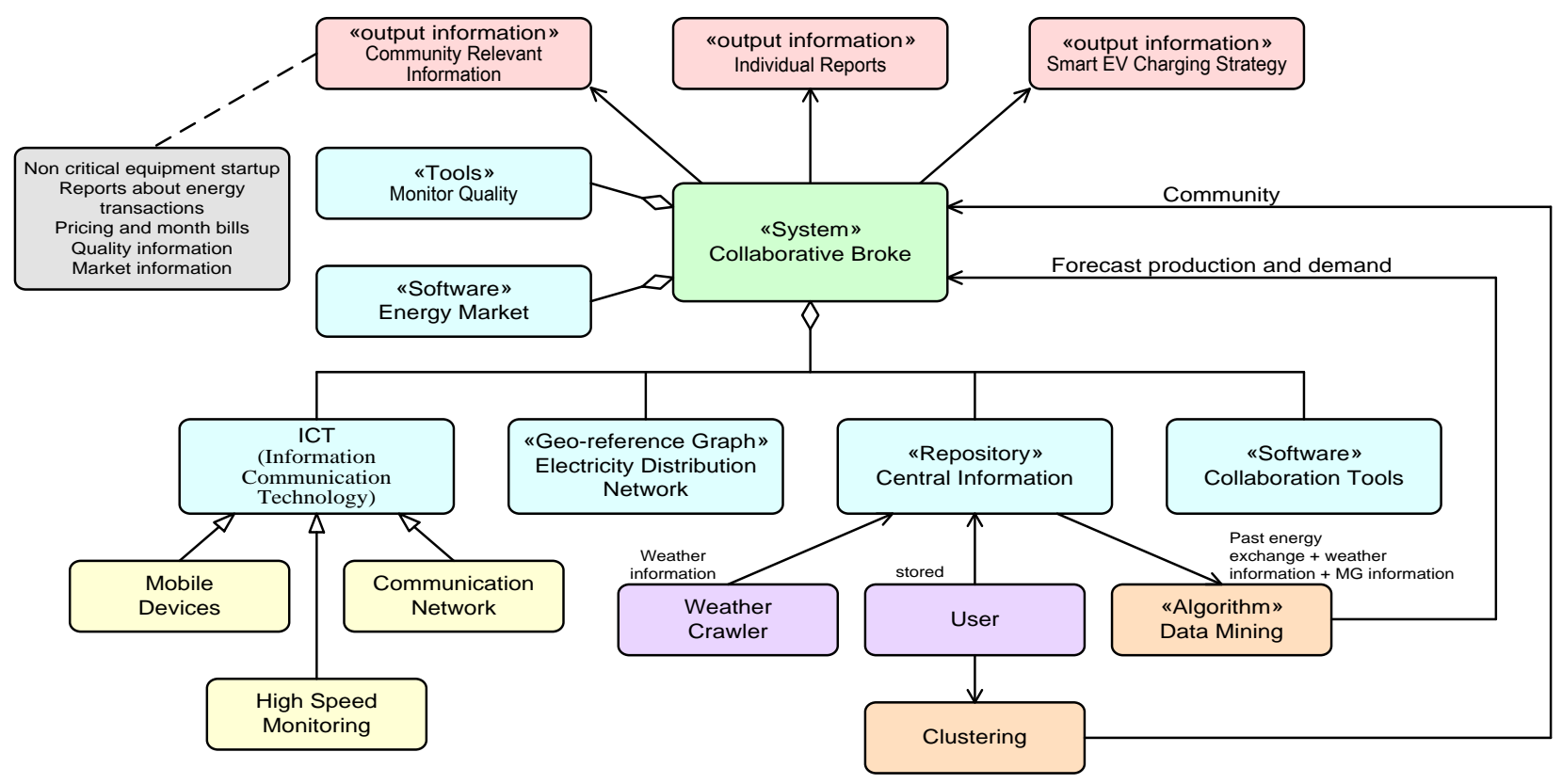

Figure 2. Main system modules.

more serious every year, the energy consumption is inevitably growing. This is especially significant as the large part of the world is starting its development and great countries, as China and India are demanding their share of life standard. New stakeholders appear in this open market: (1) Broker of electric energy services is an entity or company that acts as a middleman in a marketplace in which those services are priced, purchased, and traded. A broker does not take title on available transactions, and does not generate, purchase, or sell electric energy but facilitates transactions between buyers and sellers. If a broker is interested in acquiring a title on electric energy transactions, then it is classified as a generator or a marketer. A broker may act as an agent between a producer, or an aggregation of generating companies, and marketers; (2) Aggregator is an entity or a company that combines customers into a buying group. The group buys large blocks of electric power and other services at cheaper prices. The aggregator may act as an agent (broker) between customers and retailers. When an aggregator purchases power and re-sells it to customers, it acts as a retailer and should initially qualify as a retailer. Our collaborative system has the function of these two entities.

\section{COllaborative AgGregator BroKer FOR DER}

Our investigation proposal is to bring computer science work on software development, Web 2.0, geographic information systems, mobile computation, wireless communication to create a system to support DER energy exchange, define local prices and coordinate energy exchange from local community to big producers. The main modules of the proposed system illustrated on Figure 2, are:

1) Central Repository, stores information about: (1) user energy consumption (amount and time); (2) energy production with available information of power; (3) energy supplier and source (e.g., hydropower, wind power, photovoltaic, etc); (4) energy prices; and (5) weather information (temperature, wind direction and speed, rain amount, solar radiation, etc). A proper interface is created for user profile, creation and manipulation. This information data is worked under Data mining approach for consumption data analyses. An example of this is the Naïve Bayes (NB) showed. We implemented a weather crawler, based on a web robot to pick weather in web crawler formation from predefined sites and store this information on this information repository. Community creation is based on clustering available user profiles, based mainly on geographical position;

2) Information Communication Tools (ICT): mainly are: communication networks for information exchange; mobile devices for user real time information access (like PDA or IPhone) to receive and send control information for charging the EV batteries and also for system interaction and high-speed digital monitoring, to take care of energy transactions. Since these smart meters aren't deployed yet, we simulate these consumptions, to get working data, details of this see [10];

3) Energy Market function, see section B.

4) A collaboration software tool has as goal to help the people involved in a common task. It allows several independent computers working together, through an internet connection. In a SG context it is very important to establish patterns related to the produced and consumed energy from MG and the profiles of the consumers. Collaboration software tool, see section C.

5) Geo-reference graph based on electricity distribution network, a description of this is found in [10]. The Geo-Reference Graph for the electrical distribution network, allows computational data manipulation, such as distance calculation, identification of power limitation, and identification of user communities. 


\section{A. Repository of Information, Weather Information and Data Mining}

A deterministic approach to forecast MG production is complex, because wind power depends on the type of turbine, location (urban versus rural), high, orientation and wind speed. In solar generation the power generation depends on the environmental factors, mainly the irradiation and the cell temperature. Each case should be analyzed and this should raise a complex scenario. To avoid this and since we aren't looking for an accuracy prediction, we propose a approach based on data mining. The idea is to store past production with main weather factors that influences MG production, such as wind speed and direction, temperature and weather condition. So a flexible structure needed to store and retrieve different data was created. For this task a database is used to store all transactions (EV charging and discharging and also MG production) data, weather information and user profile information. Several approaches using data mining algorithms can be used for knowledge extraction: Past transaction data can be used to try to identify, with clustering approaches, main periods of consumption and production, trends with the identification of the main behavior. We implemented a Weather crawler, based on a web robot to pick weather information from predefined sites. In our case Portuguese weather site. Details on this can be found at [10] and Figure 3 that shows examples of information for wind and temperature. Also by manipulating available data we can perform several reports, like: home energy consumptions, weekly, monthly and annual energy expenses, price variation of electricity, charging periods, among others.

Naïve Bayes (NB) can be used to relate consumption and MG production to weather information (temperature, wind speed and direction and also humidity with raining information), a small example is shown in Table 1. Production capacity is divided in $\mathrm{n}$ classes (configurable number, get from clustering analyses of past data). In our

\begin{tabular}{|c|c|c|c|c|c|c|c|c|c|}
\hline \multirow[b]{2}{*}{ Data } & & \multirow[b]{2}{*}{$\begin{array}{c}\text { Mar total } \\
(m)\end{array}$} & \multicolumn{3}{|c|}{ Latitude: $40^{\circ} 08^{\circ} 30^{\prime \prime} \mathrm{N}$} & \multicolumn{3}{|c|}{ Longitude: $08^{\circ} 52^{\prime} 42^{\prime \prime} \mathrm{W}$} & \multirow{2}{*}{$\begin{array}{l}\text { Profundidade: } 9 \text { m } \\
\text { Temp.Água } \\
\left({ }^{\circ} \mathrm{C}\right)\end{array}$} \\
\hline & & & $\begin{array}{c}\text { Ond. } \\
(m)\end{array}$ & $\begin{array}{l}\text { Dir. } \\
\text { ond. }\end{array}$ & $\begin{array}{c}\text { Vaga } \\
(m)\end{array}$ & $\begin{array}{l}\text { Vento } \\
\text { (nós) }\end{array}$ & $\begin{array}{l}\text { Dir. } \\
\text { vento }\end{array}$ & Sets & \\
\hline \multirow{4}{*}{$\begin{array}{c}2011-07-29 \\
\left(6^{2} \text { feira }\right)\end{array}$} & $\mathrm{HOO}$ & 1.1 & 0.5 & $\rightarrow$ & 1.0 & 15.6 & $\downarrow$ & & 15.4 \\
\hline & H06 & 1.0 & 0.4 & $\rightarrow$ & 0.9 & 13.6 & $\downarrow$ & & 15.4 \\
\hline & $\mathrm{H} 12$ & 0.9 & 0.3 & $\rightarrow$ & 0.8 & 9.7 & $\downarrow$ & & 15.5 \\
\hline & $\mathrm{H} 18$ & 1.0 & 0.3 & $\rightarrow$ & 0.9 & 17.5 & $\downarrow$ & * & 14.5 \\
\hline \multirow{4}{*}{$\begin{array}{l}\text { 2011-07-30 } \\
\text { (sábado) }\end{array}$} & $\mathrm{H} 0 \mathrm{O}$ & 1.1 & 0.3 & $\rightarrow$ & 1.0 & 19.4 & $\downarrow$ & * & 14.5 \\
\hline & H06 & 1.1 & 0.3 & $\rightarrow$ & 1.1 & 19.4 & $\downarrow$ & * & 14.5 \\
\hline & $\mathrm{H} 12$ & 1.1 & 0.3 & $\rightarrow$ & 1.0 & 17.5 & $\downarrow$ & * & 14.5 \\
\hline & H18 & 1.1 & 0.3 & $\rightarrow$ & 1.1 & 21.4 & $\downarrow$ & * & 14.5 \\
\hline \multirow{4}{*}{$\begin{array}{l}\text { 2011-07-31 } \\
\text { (diomingo) }\end{array}$} & $\mathrm{HOO}$ & 1.2 & 0.3 & $\rightarrow$ & 1.1 & 21.4 & $\downarrow$ & * & 14.5 \\
\hline & H06 & 1.1 & 0.3 & $\rightarrow$ & 1.1 & 19.4 & $\downarrow$ & * & 14.5 \\
\hline & $\mathrm{H} 12$ & 1.0 & 0.3 & $\rightarrow$ & 1.0 & 15.6 & $\downarrow$ & * & 15.5 \\
\hline & $\mathrm{H} 18$ & 0.9 & 0.2 & $\rightarrow$ & 0.8 & 13.6 & $y$ & * & 15.5 \\
\hline \multirow{4}{*}{$\begin{array}{c}2011-08-01 \\
\left(2^{2} \text { feira }\right)\end{array}$} & HOO & 0.8 & 0.2 & $\rightarrow$ & 0.8 & 15.6 & $\downarrow$ & & 15.5 \\
\hline & HOG & 0.8 & 0.2 & $\rightarrow$ & 0.8 & 15.6 & $\downarrow$ & & 15.5 \\
\hline & $\mathrm{H} 12$ & 0.7 & 0.2 & $\rightarrow$ & 0.7 & 11.7 & $\downarrow$ & & 15.5 \\
\hline & $\mathrm{H} 18$ & 0.7 & 0.2 & $\rightarrow$ & 0.6 & 11.7 & $\downarrow$ & & 15.5 \\
\hline \multirow{3}{*}{$\begin{array}{c}2011-08-02 \\
\left(3^{2} \text { feira }\right)\end{array}$} & $\mathrm{H} 0 \mathrm{O}$ & 0.7 & 0.2 & $\rightarrow$ & 0.7 & 13.6 & $\downarrow$ & & 15.5 \\
\hline & H06 & 0.7 & 0.2 & $\rightarrow$ & 0.7 & 13.6 & $x$ & & 15.5 \\
\hline & $\mathrm{H} 12$ & 0.6 & 0.2 & $\rightarrow$ & 0.6 & 7.8 & $x$ & & 16.6 \\
\hline
\end{tabular}

Figure 3. Wind effect and weather information (windy and temperature) taken from weather sites for Lisbon [11]. implementation $\mathrm{n}=10$ and classes are defined based on percentage of production capacity; class 0 is zero production, class 1 is performed from 0 to $10 \%$ of production and class ten if we reach maximum production. More class means $m$ Wind and temperature were also discretized in a pre-defined class. Time is also a discrete variable. In our example we simulate one day that have only one class (corresponding to all consumption and production in a day), but in a real case more classes should be added more class. In the literature several authors divide the hour in 20 to 10 minutes events, so the number of class goes from $3 * 24=72$ to $6 * 24=144$. Wind speed and directions is correlated to pre-defined classes that characterize local Eolic production and temperature is dived in interval classes. In our case we divide wind production capacity in 7 class ( 0 to 6 ), see Figure 3 and temperature in 5 class (1 to 1). Renewable production is more dependent in wind speed than solar with temperature. This class is a configuration parameter, more class means more control dependence on this parameters but estimation complexity increase. So Table 1 shows a small example how NB algorithm works, showing the probability of an event happening. In this case we want to know for current forecast sun with temperature and wind in class 2 . Based on historical data (in case ten events) NB shows the probability for $\mathrm{p} 1$ to p10. For more details see [10].

TABLE I. NB APPROACH FOR A SMALL EXAMPLE

\begin{tabular}{|c|c|c|c|c|}
\hline Day & Weather & Temperature & Wind & Production \\
\hline 1 & Sun & 2 & 3 & 3 \\
\hline 2 & Cloudy & 1 & 5 & 4 \\
\hline 3 & rain & 4 & 1 & 2 \\
\hline 4 & Sun & 5 & 4 & 9 \\
\hline 5 & Sun & 3 & 2 & 4 \\
\hline 6 & rain & 1 & 2 & 1 \\
\hline 7 & Cloudy & 3 & 2 & 2 \\
\hline 8 & Cloudy & 4 & 6 & 5 \\
\hline 9 & rain & 3 & 3 & 3 \\
\hline 10 & sun & 3 & 2 & 4 \\
\hline 11 & sun & 2 & 2 & $? ? ?$ \\
\hline \multicolumn{5}{|c|}{$\mathrm{P}($ production $)=0.1(10$ classes $)$} \\
\hline \multicolumn{5}{|c|}{$\mathrm{P}(\operatorname{sun} \mid \mathrm{p} 3)=1 / 2($ appears one in two examples of $\mathrm{P} 3)$} \\
\hline \multicolumn{5}{|c|}{$P(\operatorname{sun} \mid p 4)=2 / 3($ appears 2 in 3 examples of $P 4)$} \\
\hline \multicolumn{5}{|c|}{ the same four others examples } \\
\hline \multicolumn{5}{|c|}{$\mathrm{P}(\mathrm{p} 1 \mid \mathrm{sun}+\mathrm{T} 2+\mathrm{W} 2)=\mathrm{P}(\mathrm{p} 1) \times \mathrm{P}(\operatorname{sun} \mid \mathrm{p} 1) \times \mathrm{P}(\mathrm{T} 2 \mid \mathrm{p} 1) \times \mathrm{P}(\mathrm{W} 2 \mid \mathrm{p} 1)$} \\
\hline \multicolumn{5}{|c|}{$\mathrm{P}(\mathrm{p} 2 \mid \mathrm{sun}+\mathrm{T} 2+\mathrm{W} 2)=\mathrm{P}(\mathrm{p} 2) \times \mathrm{P}(\operatorname{sun} \mid \mathrm{p} 2) \times \mathrm{P}(\mathrm{T} 2 \mid \mathrm{p} 2) \times \mathrm{P}(\mathrm{W} 2 \mid \mathrm{p} 2)$} \\
\hline
\end{tabular}

From this particular example we will have production capacity based on a probability approach. Since we aren't looking for accuracy prediction and most results follow a certain pattern. In this case p3 and p4 have highest 
probability. If we have installed a capacity of $3 \mathrm{~kW}$ this means under these conditions we are able to generate around $1 \mathrm{~kW}$.

\section{B. Energy Market and Smart grid Integration}

Energy Market participation will require a detail control about electricity flow, and registered users would like to control charging or discharging process, associated with the electricity prices. These prices are depending on the supplier and time and local broker picks from a pre-defined server on a standard XML file. Related to the MG the main function is to manage the produced and consumed energy in conjunction with the needs of the consumers. In this scenario in Figure 4 is shown a MG with: the micro solar photovoltaic panels (which only produce energy); the micro wind turbines (which only produce energy); the EV (which can receive or provide energy); and the energy storage systems (as the EV can receive or provide energy). Beyond the flow of energy between the parts, there is also the sharing of information, controlled by the collaborative broker. In this figure also are shown the blocks of the maximum power point tracker (MPPT) (for the micro solar photovoltaic panels and micro wind turbines), and the blocks of the AC-DC and DC-AC converters to adjust the levels of the voltages and the current between parts.

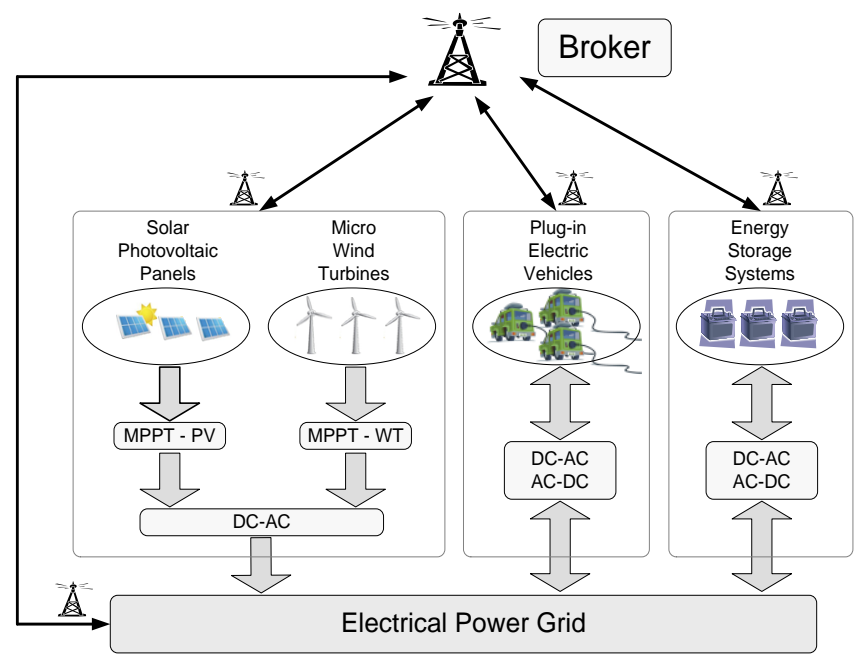

Legend: $\leftrightarrow$ Data $\Leftrightarrow$ Electrical Energy

Figure 4. Integration of the MG in electrical power grid controlled by a broker.

\section{Collaboration tool, User Profile and community}

User profiles related with their routines are created based in two main characteristics:

1) The EV type, mainly: the technology of the batteries (as Lead-Acid, Nickel or Lithium); the capacity of batteries in $\mathrm{kWh}$; the characteristics of the batteries for receive or deliver energy taking into account different rates of charging or discharging; and the SOC (State of Charge) and $\mathrm{SOH}$ (State of Health) of the batteries;
2) Related to the EVs aiming the user profile and the community, other important characteristic is the data and the time of the travel, and the $\mathrm{km}$ planned to perform it. This is particular important to define the energy which the EV owner can sell to the MG, or the needed energy to charge the batteries with fast charge.

How does a group of interested stakeholders collaborate to create real-world DER pilot programs that benefit multiple stakeholders? The following outlines important questions to address and steps that can be taken towards a common goal. In a SG scenario, there must be a collaborative process between electrical power grid, EV, MG, and EM. In this collaboration, the distribution network uses the shortest path (less impedance) to deliver production excess and $\mathrm{EV}$, if available, can store this local production excess. If $\mathrm{MG}$ generation doesn't have a local EV, the network can deliver to the nearest EV neighbor establishing a collaborative process. Also if EV SOC (state of charge) is about drivers' requirements, neighbors can take EV energy. Non critical equipment (e.g. washing machine and others) can be started when there is a local production excess. Recording data can show periods of consumption is lower and this machines can be postponed to this period (in a SG it is possible to start this equipment's taking into account real time information). This collaboration is controlled by the central broker, for accounting purposes and the price is established between the local production and local demand. The system will work always above big producers' prices and will always try to minimize energy transitions outside the community. Community is mainly defined by network distribution topology that could be reached and controlled by a collaborative broker and the energy can flow in different ways, as shown in Figure 5.

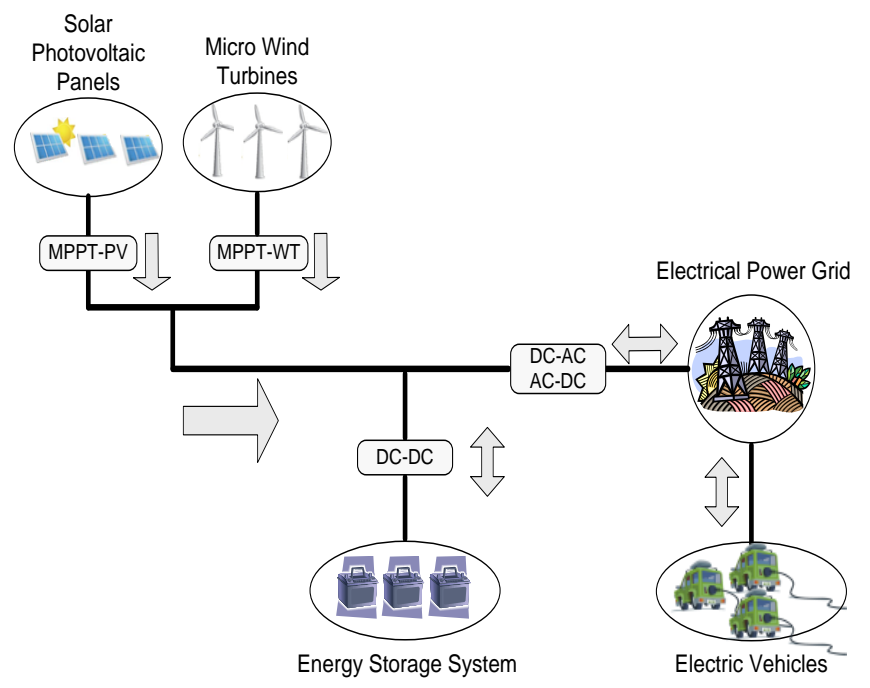

Figure 5. Flux of energy in a MG.

As previously said the flow of energy is controlled by the central broker. This control is useful in many aspects, mainly when the MG has capability to produce energy, but the electrical power grid does not need to receive energy. In this 
scenario, with the collaboration within the different parts in the SG, the energy produced by MG can be distributed to the EV or to the consumers. This distribution of energy should take into account the production and sale costs. Prices should change based on production capacity and energy needs. So the prices of electricity vary in time, but for that we need the measurement capability at the consumers. These meter devices have as only inconvenience the price. If the price differentials between hours or time periods are significant, customers can respond to the price structure with significant changes in energy use, reducing their electricity bills if they adjust the timing of their electricity usage to take advantage of lower-priced periods and/or avoid consuming when prices are higher. Customers' load use modifications are entirely voluntary. Market based solutions also give solid background to develop new business opportunities for example to aggregators. The main obstacle to introduce more price granularity at consumer's level is the costs of installing and monitoring the meters.

\section{CONCLUSIONS}

This paper describes the work that has been developed in order to provide a conceptual system to handle DER and acts like a market broker. Also collaboration is a hot topic today with the success of social networks. Applying the same principles to these local communities a lot of synergies can be generated towards a common goal, reduce the electricity invoice at the end of the month and handle the MG as a market player.

This upcoming reality needs new technology that will be available with SG full implementation (e.g. energy suppliers must be able to schedule resources, manage aggregation, and communicate both the scarcity and surplus of energy supply over time, consumers can remotely control their consumption, start/stop equipment).

As a conclusion of this analysis it can be said that the increased penetration of MG associated with $\mathrm{EV}$ in an open market have a great potential. Local production and distribution minimize transportation loses. Still a lot needs to be done, such as new legislation as well as implementation of metric devices.

\section{ACKNOWLEDGMENT}

This work is financed by FEDER Funds, through the Operational Programme for Competitiveness Factors COMPETE, and by National Funds through FCT Foundation for Science and Technology of Portugal, under the project PTDC/EEA-EEL/104569/2008 and the project MIT-PT/EDAM-SMS/0030/2008.

\section{REFERENCES}

[1] D.V.Dolle "Intelligrid Architecture," Electricity Innovation Institute (2010, 29 December). EPRI [Online]. Available: http://www.epriintelligrid.com/intelligrid/docs/Intelligrid_Intro_081804.pdf

[2] Gridwise Project (2010, 29 December). Gridwise [Online]. Available: http://www.gridwise.org/

[3] C.Andrieu, M.Fontela, B.Enacheanu, H.Pham, B.Raison, Y.Besanger, M.Randrup, U.Nilsson, R.Kamphuis, G.Schaeffer, "Distributed Network Architectures D1.7," 2005, 30 August. (2010, 29 December) CRISP

[Online].

Available:http://www.crisp.ecn.nl/deliverables/D1.7.pdf

[4] EUDEEP project (2010, 29 December). EUDEEP [Online]. Available: http://www.eudeep.com/

[5] IRED project (2010, 04 January). IRED [Online]. Available: http://ired2.iset.uni-kassel.de/

[6] M.C.BenHabib, J.Duarte, M.Hommelberg, R.Kamphuis, C.Warmer, "Power Electronic System and ICT-requirements for novel electricity distribution grids," Flexible Electricity Grids, July, year:2006

[7] Electricité de France, " Le Micro Réseau : 30 ans d'activité" Direction des Etudes et Recherches, Departement FCR, year:1986.

[8] L.Thanh,R.Caire,B.Raison,S.Bacha,F.Blache,R.Kamphuis,C.Warmer, N.Hatziargyriou,A.Dimeas,F.Bliek,H.Niesing,F.Miralles, "High Level Specification of the Functionality for novel electricity distribution grids," Deliverable D2.1, Integrated ICT-platform based Distributed Control in electricity grids with a large share of Distributed Energy Resources and Renewable Energy Sources, 17 September 2008.

[9] V.Monteiro, J. C. Ferreira, G. Pinto, D. Pedrosa, J. L.Afonso, "iV2G Charging Platform", IEEE-ITSC, 13th International IEEE Conference on Intelligent Transportation Systems, pp.409-414, 19-22 Sept. 2010.

[10] João C. Ferreira, Alberto Silva and João L. Afonso. Agent based approaches for Smart charging strategy for Electric Vehicle. EVTEC 11 (1st International Electric Vehicle Tecnology Conference), 17-19 May 2011, in Yokohama, Japan.

[11] Instituto de Meteorologia de Portugal (2011, 29 July). METEO [Online]. Available: http://www.meteo.pt/pt/maritima/costeira/ 